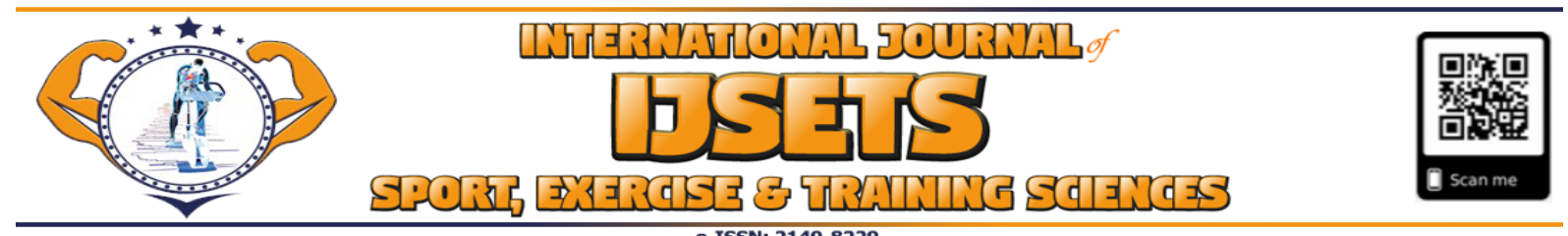

\title{
The Importance of Early Diagnosis, Education and Physical Activity in Children with Autism
}

\author{
Yüksel SAVUCU
}

Keywords

Autism,

Early Diagnosis,

Education,

Physical Activity importance of early diagnosis, education and physical activities on autistic children by reviewing the literature.

Although a diagnostic criterion of children with autism does not involve incapacitating to cover motor skills, studies indicated that motor deficits and delays in children with autism are possible. It is generally known that regular physical exercises and social activities promote the physical and mental health of these children.

The difficulties with social interactions that children with autism experience mainly pertain to a lack of understanding of the behavior of others resulting from an inability to adequately interpret consider or react to the social and emotional signals of others as communicated through eye contact and facial expressions.

Individuals with autism are ensured to be in social life thanks to early diagnosis, control of autism, appropriate training and rehabilitation programs. Especially for these people, physical activity is one of the most effective ways of establishing healthy relationships not only at home but also in all areas of life at the stage of education and rehabilitation.

\section{INTRODUCTION}

Autism or autistic disorder is defined as a developmental failure, one of the categories under the heading of autistic spectrum disorders (ASD) or pervasive developmental disorders. Autism that appears during the first 3 years of life is characterized by communication and social interaction problems, language development, and restricted/repetitive behaviors and interests (Doyle \& Iland, 2004).

In the Special Education Services Regulation (2006) in our country, the individual whose limitation in social interaction, verbal and non-verbal communication, interests and activities arises in early childhood and needs special education and support education services because of these characteristics (Özer, 2001).

It is considered to come about as a result of a process that impacts the structures or the functions of the brain and the nervous system. A significant number of individuals diagnosed with ASD also have mental retardation at different levels. The prevalent opinion is that autism can have genetical basis and is triggered by environmental factors. The physical development of children with autism and their physical appearance do not differ from other children. It can be seen four-five times more in males than females (Pegasus Yaşam Dergisi, 2019).

Autism can generally be observed along with other inadequacies such as mental disablement, learning difficulty and hyperactivity. $30-40 \%$ of autistics are mentally disabled. In $10 \%$ of these people, there are extraordinary skills called Savant. In cases when they are Savant, superior memory, mathematical and calculation, artistic and musical skills are observed. Contrary to common belief, it is not true that all autistic children are Sarvants that have extraordinary skills. In this study, it emphasized the importance of early diagnosis, education and physical activities on autistic children (Pegasus Yaşam Dergisi, 2019).

\section{Symptoms of Autism}

We can collect the symptoms of autism under two titles as Problems with Social Communication and Interaction and Repeating/Compulsive Behaviours and Limited Interest and Activity (Pegasus Yaşam Dergisi, 2019).

${ }^{1}$ Faculty of Sports Sciences, Firat University, Elazığ/Turkey ORCID ID:0000-0002-2749-6806 
Under Problems with Social Communication and Interaction; we can list not responding when they are called, not establishing eye contact, acting as if you are not there, not developing friendships, acting in different when shown interest, not starting conversations or speaking indecipherably, not keeping up with the conversation, repeating some words inanely, and not taking part in their friends games.

For Repeating/Compulsive Behaviours and Limited Interest and Activity we can list being too interested in certain objects, i.e. watching the washing machine for hours, excessive dependence on order and routine, displaying excessive reaction to changes, to rock or convulse, walking on tip toes, displaying excessive reaction or non against sensual stimuli like certain sounds, textures and scents (Özer, 2001).

If families observe behaviours different from their peers and the symptoms cited above, it would be in their best interest to consult an expert psychiatrist specialising in autism. Symptoms do not mean a thing by themselves. You need to take note if symptoms are observed in both of these areas (Pegasus Yaşam Dergisi, 2019).

\section{Prevalence of Autism}

Autism is fast becoming more commonly observed: In 1985, while 1 out 2500 children had it, today the number has gone up to 1 in each 59 children. A child is diagnosed with autism every 20 minutes. Therefore, parents have to show the necessary sensitivity.

Unfortunately, there are not any reliable statistics for our country. According to the population projection we make by taking the 1 in each 59 children ratio acknowledgement in the world as a benchmark, we can say that there are around 434 thousand autistics children between the ages of 0-18, waiting to benefit from healthcare and social services. When we project it to the population, it is estimated that there are approximately 1,400.000 individuals with autism in our country and there are more than 5,550.000 family members affected by this situation (Pegasus Yaşam Dergisi, 2019).

\section{Treatment of Autism and Early Diagnosis}

The importance of education for children with autism has been proven by scientific methods. Today, the only known remedy and cure for autism is early diagnosis, followed by continuous and intensive special education and rehabilitation. In around $50 \%$ of the children that get the right training in the required intensity thanks to early diagnosis, symptoms of autism can be taken under control, improvement and great advances can be observed and even some of autistic children can be no different than their peers when they get to puberty. However, the American Psychiatric Association reports that some common features related to impaired social interaction, communication disorder and restricted/repetitive interests and behavior are important as diagnostic criteria for children with autism (American Psychiatric Association, 2000).

Individuals with autism are ensured to be in social life thanks to early diagnosis, control of autism, appropriate training and rehabilitation programs. Especially for these people, physical and social activities is one of the most effective ways of establishing healthy relationships not only at home, but also in all areas of life at the stage of education and rehabilitation.

The most important thing here is to diagnose at an early age and provide them with an intensive training of up to 30 hours a week. Organizations and associations such as Tohum Autism Foundation, established for this purpose, continue their activities with full strength in order to bring children into society and social life through early diagnosis and education, and to become independent and productive individuals that will contribute to their families and society (Pegasus Yaşam Dergisi, 2019).

\section{Activities for Children with Autism}

The importance of education and activities for children with autism has been proven by scientific methods. As the causes of autism are not known precisely, it is not possible to take precautions today. However, starting education at an early age and preferring scientific methods are important in the development of these individuals. Along with the special education used in the development of mental elements and social activation, physical education, which is an effective tool to prevent various health problems, is also important. We see that these specially organized training programs not only improve the physical condition but also reduce some health problems and body mass indexes of individuals with severe autistic disorders (World Health Organization, 2002).

Autistic children cannot play with their peers due to peer and social integration difficulties, communication failures, repetitive/restricted interests and activities, and they have difficulty in participating in various physical and social activities (Block, Block \& Halliday, 2006). In addition to 
the current inadequacies of these children, limiting support to physical activity opportunities and people being unaware of physical activities for children with autism also causes the child with autism to have lower motor performance than their peers (Reid, 2005; Sandt \& Frey, 2005; Pan \& Frey, 2006; Baranek, 2002; Dewey, Cantell and Crawford, 2007; Piek \& Dyck, 2004; Todd \& Reid, 2006).

However, the motor development of autistic children is normal or very close to normal. By improving sports skills, physical fitness levels can be improved. Sports activities enable them to gain self-confidence, experience a sense of accomplishment and competition, and develop friendship relationships. In this way, the opportunity to be accepted, useful and productive individuals in the society is given (Findlay \& Coplan, 2008).

It can be seen that autistic children learn later, due to the fact that they have little or no ability to imitate some movements that require the use of great muscle motor skills such as skipping, dancing, swimming. Small muscle motor skills such as paper cutting, cube throwing and string beads are also observed to be quite weak. It is seen that autistic children sometimes show a different appearance than normal when using their hands (walking on fingertips, repeating certain movements, swinging back and forth on one foot, turning around themselves, etc.). However, they are considered to be hyperactive (very mobile) or hypoactive (less mobile) as other motor behavior features (Özer, 2001).

Participation in sports, games and group activities is a convenient and effective method as it increases socialization skills and social well-being in autistic individuals. It was observed that selfesteem increased, assertiveness and self-control characteristics improved as well as the development of physical abilities and physical appearances in participating in such activities. Especially the majority of autistic children who participate in recreational activities seem to prefer activities without social interaction (Berkeley, Zittel, Pitney \& Nichols, 2001; Pan, 2010).

Although there are exceptions, it is not impossible to do sports activities for children with autism. Football, basketball, volleyball, handball, etc. with a high level of strength and coordination. Advanced social communication skills are required in team sports. Autism is a disorder in which these skills are lacking. For this reason, individuals with autism are interested in team sports, which also improves their good communication skills. In addition, there is a decrease in stimulating behaviors and other inappropriate social behaviors.

Autism often causes weakening in muscle tone and coordination problems. Such a situation may cause difficulties in activities in autistic children. Pool activities, hiking, dodgeball, badminton, bowling etc. activities enable autistic children to participate in the activity without using too much force and offer the opportunity to be part of a sports organization (Moor, 2008; Auxter, Pyfer \& Huettig, 2001; Beckerleg, 2009; Martinez, 2006; Moor, 2008).

In addition, autistic children can communicate with animals more easily than humans can. Although horse riding is expensive, it is still a great activity for children with autism. In addition, combat sports such as karate, judo, taekwando, and aikido can combine predictability and elements of the structure with the challenges of physical interaction with other people. For many children with autism, combat sports are also a great way to develop physical skills along with self-esteem. They are also suitable activities for them in sports such as walking and cycling, where they can enjoy exercise and enjoy nature without the pressure of intense social communication in nature (Pitetti et al. 2007; World Health Organization, 2002).

Despite the relative success of standard ASD treatments, interest in the potentially beneficial effects of physical exercise has increased in recent years. Systematic research in this area is still relatively small and is mostly based on small participant groups. The overall picture that has emerged from the current results is that physical exercise is effective not only in improving the physical condition, but also in reducing the discordant behavior patterns of people with Autism (Lancioni \& O'Reilly, 1998).

\section{CONCLUSION AND RECOMMENDATIONS}

More research is needed on the impact of individual and group interventions, especially on the vulnerabilities in communication deficits, as well as on the extent to which health-related physical fitness effects depend on the severity of autistic symptoms.

Children with autism cannot sufficiently benefit from difficulties in maintaining leisure time such as social isolation, restricted communication skills, poor eye contact, stereotypical movements and 
behaviors, inadequate activity opportunities and therefore physical and social activities. Social and physical activities for children with autism should be developed according to their preferences and needs in natural settings. Adequacy of the area, noise, number of people in the environment, material selection, determination of teaching strategy and behavioral control strategies are basic issues.

Various facilities and social activity programs should address this gap in physical activity. Children with autism tend to be similar to their peers who do not have autism disorders in their physical activity patterns; related benefits and future research should be discussed.

\section{REFERENCES}

American Psychiatric Association, APA. (2000). Diagnostic and statistical manual of mental disorders: Text revision (4th ed.). pp. 69-70. Washington, DC: American Psychiatric Association.

Auxter, D., Pyfer, J. \& Huettig, C. (2001). Principles and methods of adapted physical education and recreation (9 Ed.). (pp. 480-488). New York: McGraw-Hill.

Baranek, G. T. (2002). Efficacy of sensory and motor interventions for children with autism. Journal of Autism Developmental Disorder, 32, 397- 422.

Beckerleg, T. (2009). Fun with Messy Play: Ideas and Activities for Children with Special Needs. (pp. 83-91). London: Jessica Kingsley Publishers.

Berkeley, S. L., Zittel, L. L., Pitney, L. V. \& Nichols, S. E. (2001). Locomotor and object control skills of children diagnosed with autism. Adapted Physical Activity Quarterly, 18, 405-416.

Block, M. E., Block, V. E. \& Halliday, P. (2006). What is autism? Teaching Elementary Physical Education, 17, 7-11.

Dewey, D., Cantell, M. \& Crawford, S. G. (2007). Motor and gestural performance in children with autism spectrum disorders, developmental coordination disorder, and/ or attention deficit hyperactivity disorder, Journal of the International Neuropsychological Society, United States of America, 13, 246- 256.

Doyle, B. T. \& Iland, E. D. (2004). Autism spectrum disorders from A to Z. (pp. 35-37). Texas: Future Horizons.

Findlay, L. C., \& Coplan, R. J. (2008). Come out and play: Shyness in childhood and the benefits of organized sports participation. Canadian Journal of Behavioural Science, 40; 153-161.

Lancioni, G.E., O'Reilly, M.F. (1998). A Review of research on physical exercise with people with severe and profound developmental disabilities. Research in Developmental Disabilities, 19; pp. 477-492.

Martinez, C. A. (2006). Adapted aquatics for children with autism. Teaching Elementary Physical Education, 17, 34-36.

Moor, J. (2008). Playing, Laughing and Learning with Children on the Autism Spectrum: A Practical Resource of Plat Ideas for Parents and Carers (2th ed.).(pp. 141-180).London: Jessica Kingsley Publishers.

Özer, D. S. (2001). Engelliler İçin Beden Eğitimi ve Spor. Nobel Yayın Dağıtım, Ankara.

Pan C.Y. \& Frey C.G. (2006). Physical activity patterns in youth with autism spectrum disorders. Journal of Autism Developmental Disorder, 36, 597- 606.

Pan, C.Y. (2010). Effects of water exercise swimming program on aquatic skills and social behaviors in children with atism spectrum disorders. Autism, 14, 1, 9-28.

Pegasus. Yaşam Dergisi. (2019). s. 108-112, Aralık.

Piek, J. P. \& Dyck M. J. (2004). Sensory-motor deficits in children with developmental coordination disorder, attention deficit hyperactivity disorder and autistic disorders. Human Movement Science, 23, 475-488. 
Pitetti, K.H., Rendoff, A.D., Grover, T., Beets, M.W. (2007). The efficacy of a 9-month treadmill walking program on the exercise capacity and weight reduction for adolescents with severe autism. Journal of Autism and Developmental Disorders, 37; pp. 997-1006.

Reid, G. (2005). Understanding physical activity in youths with autism spectrum disorders. Palaestra, 21, 6-7.

Sandt, D. D. R. \& Frey, G. C. (2005). Comparison of physical activity levels between children with and without autistic spectrum disorders. Adapted Physical Activity Qurterly, 22, 146159.

Todd, T. \& Reid G. (2006). Increasing physical activity in individuals with autism. Focus on Autism and Other Developmental Disabilities, 21, 167-176.

World Health Organization. (2002). The world health report, reducing risks, promoting healthy life, WHO, Copenhagen.

\section{CITATION OF THIS ARTICLE}

Savucu, Y. (2020). The Importance of Early Diagnosis, Education and Physical Activity in Children with Autism. International Journal of Sport, Exercise \& Training Sciences - IJSETS, 6(3), 105-109. DOI: $10.18826 /$ useeabd.716110 